\title{
Effects on the Listening Comprehension of Different Non-native English Accents of Chinese Learners of English
}

\author{
Wu Jidong ${ }^{1}$, Kaniz Fatema ${ }^{2}$ J Yeboah ${ }^{3}$, \\ ${ }^{1}$ Associate Professor, Department of Foreign Languages, Nanjing Tech University, Nanjing, China. \\ ${ }^{2}$ M.A. in Foreign Linguistics and Applied Linguistics, Nanjing Tech University of China \\ ${ }^{3}$ M.A. in Foreign Linguistics and Applied Linguistics, Nanjing Tech University, China.
}

\begin{tabular}{|c|c|}
\hline Article Info & Abstract \\
\hline Article hist & Purpose: This study assessed the effects on the Listening Comprehension of \\
\hline $\operatorname{Rec}$ & Different Non-native English Accents on Chinese Learners of English. The \\
\hline anuary 2021 & study aimed to determine, first of all, the reaction of Chinese learners of \\
\hline anuary 2021 & $\begin{array}{l}\text { English to different non-native English accents. Second, it sought to } \\
\text { investigate the differences in the difficulties that Chinese learners of English }\end{array}$ \\
\hline Keywords: & face while listening to English spoken with accents native (Chinese English \\
\hline $\begin{array}{l}\text { Listening Comprehension, } \\
\text { Non-native Accent, }\end{array}$ & $\begin{array}{l}\text { accent) or non-native. Third, the study attempted to find out the relationship } \\
\text { between English spoken with the native Chinese accent and/or non-native }\end{array}$ \\
\hline Fami & English accents and listening comprehension. \\
\hline International Education. & $\begin{array}{l}\text { Methodology/Approach/Design: The sample included } 16 \text { participants } \\
\text { majoring in International Education of Chinese Language. They were } \\
\text { selected randomly for the study. Both quantitative and qualitative } \\
\text { approaches were employed to collect and analyze data. } \\
\text { Results: The findings revealed that non-native English accent plays a more }\end{array}$ \\
\hline Research Article & $\begin{array}{l}\text { important role than the native English accents in listening and } \\
\text { comprehension. The findings also revealed a listening comprehension }\end{array}$ \\
\hline Corresponding & $\begin{array}{l}\text { advantage for test-takers who are familiar with accents, in this case, the } \\
\text { Chinese non-native English accent. }\end{array}$ \\
\hline Kaniz Fatema & $\begin{array}{l}\text { Practical Implications: For a better understanding of the teaching and } \\
\text { learning process of English as a foreign language, learners or listeners need }\end{array}$ \\
\hline $\begin{array}{l}\text { Email: } \\
\text { fatemakaniz700@gmail.com }\end{array}$ & $\begin{array}{l}\text { to assess the influence of non-native accents on their listening } \\
\text { comprehension to find better ways in improving their listening skills. This } \\
\text { study contributes significantly to this field. }\end{array}$ \\
\hline & Originality/Value: This study employed multi non-native accent including \\
\hline & $\begin{array}{l}\text { African English accents. It attempted to contribute significant value in this } \\
\text { field }\end{array}$ \\
\hline & $\begin{array}{l}\text { English Speakers and they, in essence, have considerable influence on the } \\
\text { learners' listening comprehension. }\end{array}$ \\
\hline
\end{tabular}

\section{Introduction}

Yildiz(2017) in his early works posited that linguistic theory has traditionally considered native speakers as the only reliable source of linguistic data, although non-native speakers of English already outnumber the native ones. Empirical studies however claim that there has been a significant divergence from the native speaker fallacy (Philippson, 1992) towards more equal conditions for both native English speaking (NES) and non-native English speaking (NNES) teachers. Today, according to Canagarajah (2005), 80\% of the English 
teachers across the world are non-native English speakers. While the spread of English has resulted in new users and owners of the language, diversities in the English language itself have not been fully integrated. With regards to pronunciation in particular, there exists an inseparable link between a person's identity and his or her accent. This is to say that keeping an accent, in essence, is a way of displaying one's identity. For example, the English accent of an Australian is different from an American or a British; then again, the English accent of an Indian is different from that of a Ghanaian, Pakistani, Bangladeshi, or a Chinese. This is a clearly evident; however, these different accents attract different reactions from different listeners and these reactions one way or the other may, in turn, influence the listener's comprehensibility.

Listening comprehension is one of the most important skills in both second and foreign language (hereafter, L2 and FL) learning. Vandergrift (2007) claimed that L2 listening comprehension is at the heart of L2 learning and this is so because its development facilitates the development of other L2 skills. Listening comprehension is a complex psychological process of listeners' understanding of language by a sense of hearing. It is an interactive process of language knowledge and psychological activities (Guo, 2005). Nonetheless, this process is not simply decoding the message said by Ma Lihua (2002); it involves the combination of decoding of the message process with its reconstruction, as in meaning (Gilakjani, 2011). Research studies like that of Anderson-Hsieh and Kohler's (1988) have provided evidence that 'accent' can affect listening comprehension. Regardless, it should be noted that it is not necessarily a major case. In the study by Anderson-Hsieh and Kohler (1988), the speakers who were the participants of the study were assumed to have different accent strengths based on their country of origin and their English language proficiency derived from judgments of their oral proficiency - including pronunciation while conducting a listening test on North- American Learners. The study indicated that research on non-native accents is necessary when it comes to understanding any kind of listening.

In this present study, the researchers conveniently selected 5 audios with non-native English accents (Ghanaian, Pakistani, Bangladeshi, Nigerian, and Italian) based on their high number as representatives of their countries in Nanjing Tech University where the research was carried out. The study first tried to find out the reactions of Chinese English learners to the different English accents selected above. Also, the researchers did a comparative study on the reactions of the Chinese English learners towards English orals material with native Chinese speakers of English accent and non-native speakers of English accent on listening comprehension. This was to determine the level of accent preference among the participants, the differences in difficulties and the linguistic diversities (familiarity) and the effects on the learners' listening ability.

\section{Literature Review}

There is considerable research conducted on the topic 'the relationship between the speaker's accent and listening'. One of the most recent studies was carried out by Matsuura et al. (2014) who conducted a survey to determine whether or not English spoken with an accent 
less familiar to learners was comprehensible. They worked with two groups of students who listened to the same text, with some time break in between, from one familiar and one unfamiliar speaker (Canadian; familiar and Indian; unfamiliar speakers respectively). The results revealed that the students scored higher when they listened to the Canadian speaker, which suggests that familiarity with the accent facilitates listening comprehension.

Another recent study conducted by Ockey and French (2016) aimed to determine the extent to which accent strength and familiarity affect comprehension and provide a defensible direction for assessing multidialectal listening comprehension. In their studies, TOEFL test takers $(\mathrm{N}=21,726)$ were randomly assigned to listen to a common lecture given by one out of nine selected speakers, and to respond to six comprehension items; a survey designed to assess their familiarity with various accents. The results of which suggest that strength of accent and familiarity does affect listening comprehension, and these factors affect comprehension even with quite light accents (Ockey \& French, 2016, p. 8).

A similar study was conducted by Harding (2011) to find out whether listeners who share the speaker's L1 performed better on a listening tests. He found out that a shared-L1 effect in listening comprehension is at the very least possible, and in certain circumstances, clearer. Concerns about the use of only one select English accent for assessing the second language (L2) listening comprehension has become increasingly prevalent (Harding 2011; Taylor and Geranpayeh 2011; Abeywickrama 2013). Ockey \& French (2016) stated that critics of this practice of using only one select variety of English point to the changing demographics in many English-speaking contexts and argue that L2 listening assessments need to reflect these changes (Ockey \& French, 2016). They stated also that these voices contend that, given the variety of accents that may be encountered in these contexts, it may be necessary to have multidialectal listening skills to communicate successfully in English speaking contexts (Ockey, 2016). In North American universities for instance, it is not uncommon for 20-30\% of teaching assistants to have accents different from the standard United States variety (Department of Institutional Research, 2007). It follows however that, scores based on listening assessments which measure comprehension of only a selected accent may not reflect how well these test takers can perform in such a multidialectal language domain. Ockey \& French stated also that, to ensure that test-takers are prepared for diverse contexts, an argument can be made for including multiple accents on listening assessments designed to determine the extent to which test-takers will be able to communicate in such environments.

In WE (World English's) research, investigating people's attitudes toward English accents is fairly popular, and abundant studies have been reported from a variety of perspectives (Crowther et al., 2015; Munro \& Derwing, 1999). In the case of Inner Circle English accents, others investigated Expanding Circle English speaker attitudes (McKenzie, 2008).According to Matsuura (2017), other researchers investigated EFL learner attitudes toward Outer Circle varieties (Matsuura, Chiba, \& Yamamoto, 1994; Chiba, Matsuura, \& Yamamoto, 1995) and Outer Circle speakers' reactions to Expanding Circle English ((Matsuura, Chiba, \& Yamamoto, 1994). 
There are, nonetheless, concerns about the use of variety of accents on L2 listening comprehension assessments. This is because it is assumed that some test takers may be unfairly disadvantaged (Elder \& Davies, 2006; Elder \& Harding, 2008; Taylor \& Geranpayeh, 2011). Ockey\& French (2016) add that it would not be practical for each form of assessment to include every type of accent that may be used in the target language domain, which refers to the "situation or context in which the test taker will be using the language outside of the test itself" (Bachman \& Palmer (1996, p. 18). Sampling from a large number of accents could also be unfair mainly because, those unfamiliar with the accent selected for any given test form may be disadvantaged (Field 2004; Taylor, 2006). Thus, while assessing listening comprehension with speakers who have homogeneous accents may under-represent the listening construct, including speakers with multiple accents may result in an unfair disadvantage of some test takers.

Furthermore, quite a handful of research studies have investigated the effects of 'accent' on listening comprehension and failed to find an effect. Abeywickrama's (2013) study employed Brazilian, Korean, and Sri Lankan English learners to take a multiple-choice (MC) listening test in which the input was delivered by a Chinese, Korean, Sri Lankan, or US speaker. She used a one-way between-groups ANOVA, with the speaker's country of origin as the independent variable and a score on a multiple-choice speaking test as the dependent variable. Finally the results showed no significant relationship between scores on the MC listening assessment and the speakers who delivered the inputs. Ockey and French (2016) cited that Abeywickrama (2013) assumed that the speakers had an accent that reflected their country of origin, but did not provide a measure of accent in the study. They explained that because there was no measure of the strength of accent, or any other related construct such as intelligibility, used in the study; it was not clear as to what degree these accents were different from the local variety and the test takers familiarity.

Major et al. (2002) argued that the majority of research, however, suggests that a speaker's accent can affect listening comprehension scores (e.g., Eisenstein and Berkowtiz, 1981; Ekon,g 1982; Smith \& Bisazza, 1982; Anderson-Hsieh \& Kohler, 1988; Bilbow, 1989). Of particular importance to the current study is the research conducted by Anderson-Hsieh and Kohler (1988) which considered the strength of accent in the study's design and compared the listening. The first language of three of the speakers was Chinese, and the fourth speaker was North American. The results indicated that the participants had significantly higher comprehension scores for input delivered by the North American speaker than the Chinese speakers and that the comprehension was lower for Chinese speakers who had the weakest English proficiency and poorest pronunciation. More so, test takers comprehended the North American speaker significantly better than all of the L1 Chinese speakers. The Chinese speakers were assumed to have different accent strengths based on their country of origin and their English language proficiency derived from judgments of their oral proficiencyincluding pronunciation (Anderson-Hsieh and Kohler 1988 cited in Ockey \& French, 2016, p. 7). 
Studies like Anderson-Hsieh and Kohler's (1988) have provided evidence that 'accent' can affect listening comprehension, but that it is not conclusively the case that it does all the time (Ockey, 2016). A likely reason for these mixed findings is that, as Anderson-Hsieh and Kohler (1988) concluded, there are various types and strengths of accents and also based on Derwing and Munro's (2009) definition; some of which affect the listening comprehension of some listeners and not others (Ockey, 2014). He claimed that possibly the biggest threat to the validity of listening scores yielded from speakers with different accents is that, some test takers may be advantaged by familiarity with a particular accent encountered on a listening test, while others unfamiliar maybe disadvantaged. A substantial body of research suggests that familiarity with an accent positively relates to comprehensibility (Gass \& Varonis, 1984; Derwing \& Munro, 1997; Adank et al., 2009; Adank \& Janse, 2010). Adank et al., (2009) also found that listening to an unfamiliar English accent resulted in lower scores for nativespeakers of English than listening to the same input from an English speaker with a familiar accent. Bradlow and Brent (2008) suggested that such an effect could result from phonetic characteristics of speech that have the same accent which is known to be rather consistent across speakers.

In Ockey \& French's (2016) papers, two British English accents (Southern Standard and Glaswegian) and two groups of British listeners were employed. Both groups of listeners were familiar with the Southern Standard variety but only one was familiar with the Glaswegian variety. The study results indicated that familiarity with the accent led to better comprehension. A follow-up study report in the same paper, however, did not indicate that comprehension was debilitated by an unfamiliar accent but did provide evidence that processing time for comprehension was significantly greater for unfamiliar than familiar accents. The researchers assumed that the conflicting results of the two studies were because the accents for the two speakers were less prominent for the unfamiliar accents in the second study. These conflicting findings underscore the importance of clearly defining and measuring accent to determine its effect (Ockey, 2014).

Moreover, Major et al., (2002) revealed a familiarity effect for Spanish speakers, whose comprehension was higher when listening to an English speaker with a Spanish accent compared to an English speaker with a Chinese accent. On the contrary, this shared L1 hypothesis did not stand for Chinese listeners. They did not better comprehend English with a Chinese than Spanish accent. Ockey \& French (2016) found out, the speakers were assumed to have Spanish and Chinese accents based on their country of origin, and as the researchers pointed out that, their findings may be mitigated by their failure to account for item difficulty and use of a defensible measure of the strength of accent (Ockey \& French, 2016, p.8). The shared L1 hypothesis effect has been investigated by other researchers, who have concluded that it is not necessarily the shared L1 that relates to higher listening comprehension (Ockey, 2016) rather, it is familiarity based on previous exposure to the accent that dictates listening comprehension (Smith \& Bisazza, 1982; Ortmeyer \& Boyle, 1985; Tauroza \& Luk, 1997).

Harding's (2011) study took this body of research a step further by investigating possible factors that impact comprehension of unfamiliar accents. After corroborating previous 
research with a finding for greater comprehension of familiar than unfamiliar accents, Harding suggested that this may be due to misperception and the lack of ability to distinguish phonetic information, or challenges with processing speech. A clear cut distinction is made between the study of Ockey \& French (2016) and this current study, in that, their paper focused mainly on what the strength of accent and familiarity. The results of which indicated that strength of accent and familiarity do affect listening comprehension, and these factors affect comprehension even with quite light accents. However, the present study fills a gap in their study by concentrating on assessing the effects on the listening comprehension of different Non-native English accents including African English accents on Chinese learners of English. The study aimed to determine the reaction and or attitudes of Chinese learners of English to different non-native English accents. It sought to investigate the differences in the difficulties that Chinese learners of English face while listening to English spoken with accents native (Chinese English accent) or non-native. Finally, it attempted to find out the relationship between English spoken with the native Chinese accent and/or non-native English accents and listening comprehension.

\section{Methodology and Procedures}

\section{Research Design}

The researchers adapted both quantitative and qualitative approaches to collect and analyze data. Nonetheless, the study mostly follows a quantitative research approach. It consisted of 5 audio recordings of non-native English accents, listening comprehension text followed by five different sets of questions. The participants were asked to take a listening comprehension test on the different non-native English accents (Ghanaian, Pakistani, Bangladeshi, Nigerian and Italian). The non-native English accents were selected based on their high number of representation (ranged the highest first 5 international students) in Nanjing Tech University where the research was carried out. Next, the participants were asked to fill up a student's questionnaire about their authentic opinion and comprehension of the listening material after the listening comprehension test. All the participants' data collected were submitted to be analyzed using SPSS. 25 version.

\section{Research Participants}

The sample of the study included 16 participants who are students (4 males and 12 females) from Nanjing Tech University, majoring in International Education of Chinese Language. They were randomly selected to partake in the study. They all have Chinese as their mother tongue and have learned English for not less than ten years. The average of their ages is 19 years, ranging from 17 to 21 years old. The participants joined the study voluntarily and were assigned to finish 5 listening tests with the different non-native English accents. 


\section{Materials}

The 5 English listening comprehension texts used in this study were adopted from philosophical messages of almost the same length, and 5 questions followed each text read by the different non-native English speakers, which were recorded in different 5 audios. Each audio played for a maximum of 3 minutes and the test time allotted was 25 minutes in total. Participants were allowed 5 minutes for each test. The speech speed of each audio was according to announcers of CCTV about 250-260 words per minute. There is only one point that explains why this paper chose different audios for each non-native English accent and that was to prevent the participants' familiarity with the audios. To measure if the participants' preference of accents (this was measured using Likert scale questionnaire and two yes-no questions) aligned with their comprehension, each of the texts in the listening tests that had one type of questions, requiring a short answers.

\section{Procedure}

The research consisted of 5 listening tests with short break intervals and was completed in the classroom. The experimental procedures consisted of two parts: first, Participants were required to listen to 5 audios with different non-native English accents and were given 5 minutes to complete their answers to each audio on the answer sheet. Each audio was played twice for a maximum of 3 minutes each time and the test time allotted was 5 minutes. The test was done chronologically as participants were asked to finish one test before the next audio was played. A total of 25 minutes was spent on the whole test. Each test consisted of 5 questions. Secondly, to measure the level of preference of Chinese learners of English to the different non-native accents, participants were asked to answer a survey questionnaire (this was measured using Likert scale questionnaire and two yes-no questions, see appendix). This section also lasted for 10 minutes. When the time was up, all the test papers were collected.

\section{Results and Discussion}

\section{Descriptive Statistics}

To find out the answer to the first research question which aimed to determine the reaction of Chinese English to different accents, the first questionnaire was designed. From the data analysis described in the tables below, the Ghanaian oral material is the most preferred by Chinese English learners in terms of frequency as 7 participants out of the 16 preferred it. The second most preferred accent is Pakistani accent with 6, followed by the Nigerian accent with 2 participants. The Bangladeshi accent and that of the Italian had the least preference with 1 and 0 participant preference respectively. This indicates that Chinese learners found the Ghanaian accent comprehensible and the Italian English accent hard to comprehend as the frequency shows in table 1 and 5 below: 
Table 1:Accent preference for Ghanaian

\begin{tabular}{lll|l|l|l} 
& & & & Cumulative \\
Valid & & Frequency & Percent & Valid Percent & Percent \\
\hline \multirow{7}{*}{} & 1 & 6.3 & 6.3 & 6.3 \\
\cline { 2 - 6 } & Understandable & 10 & 62.5 & 62.5 & 68.8 \\
\cline { 2 - 6 } & Not understandable & 5 & 31.3 & 31.3 & 100.0 \\
\cline { 2 - 6 } & Total & 16 & 100.0 & 100.0 & \\
\hline
\end{tabular}

Source: Authors

When the participants listened to the audios, their reaction varied from one audio to another non-native accent and it is assumed that they answered the questions based on their understanding or comprehension. Among all non-native accents, they seem to understand the Ghanaian accent the most; a majority of the participant answered most of the questions correctly. As table 1 presents, among 16participants, 10participants representing $62.5 \%$ could answer almost all answers correctly and the other 5 representing $31 \%$ could answer averagely. This however represents the highest level of preference among the 5 non-native accents used in the study. The level of preference with reference to this accent can be explained in terms of sex as the speaker was the only female among the audio recordings. It has been proven in different researches that, a female has flexibility when it comes to pronunciation. This confirms the research findings of Nihart Polart (2011) regarding girls' higher performance in different L2 skills (Baker and MacIntrye 2000; Gardner et al. 2004; Kang 2000; Kissau 2006; Williams, Burden and Lanvers 2002; Wright 1999), but some of these studies also suggest that different motivational orientations are associated with higher accent ratings in the case of males and females.

Table 2: Accent preference for Pakistani

\begin{tabular}{lll|l|l|l} 
& & & & & \multicolumn{2}{c}{ Cumulative } \\
& & Frequency & Percent & Valid Percent & Percent \\
\hline Valid & 1 & 6.3 & 6.3 & 6.3 \\
\cline { 2 - 6 } & Understandable & 6 & 37.5 & 37.5 & 43.8 \\
\cline { 2 - 6 } & Not understandable & 9 & 56.3 & 56.3 & 100.0 \\
\cline { 2 - 6 } & Total & 16 & 100.0 & 100.0 & \\
\hline Source: Authors & & & &
\end{tabular}

When the participants listened to the oral material of Pakistani non-native English accent, some participants could answer all the questions. As table 2 presents, among 16 participants 6 participants representing $37.5 \%$ could answer most of the questions correctly and 9 representing $56 \%$ of the participants could barely answer 3 questions on average. Although it cannot be said hastily, even with the same speed time for all the audios, some participants still found the Pakistani audio a bit faster than their Ghanaian counterparts which made it a little difficult for the participants to catch the main ideas of the test for better comprehension. Some previous studies contrary to this findings have demonstrated that non-native speech is substantially slower than native speech (Guion et al., 2000), suggesting a general lack of proficiency and inexperience can result in slower speaking rates. The Pakistani English speaker speed rate was not slow, and also accurate in the terms of pronunciation and skill. 
Table 3: Accent preference for Nigerian

\begin{tabular}{lll|l|l|l} 
& & & & & \multicolumn{2}{l}{ Cumulative } \\
& & Frequency & Percent & Valid Percent & Percent \\
\hline Valid & & 1 & 6.3 & 6.3 & 6.3 \\
\cline { 2 - 6 } & Understandable & 3 & 18.8 & 18.8 & 25.0 \\
\cline { 2 - 6 } & Not understandable & 12 & 75.0 & 75.0 & 100.0 \\
\cline { 2 - 6 } & Total & 16 & 100.0 & 100.0 & \\
\hline
\end{tabular}

Source: Authors

Nigerian accent didn't get that much positive reaction as either the Ghanaian or Pakistani non-native accent. As table 3 presents, 3 participants representing $18.8 \%$ out of 16 could answer most of the questions of the comprehension test correctly. Though not definitive, the participants attributed this to the peculiarity of the Nigerian accent which is quite different from the way the Chinese English learners are habituated to listen. This confirms one of the most recent studies belonging to Matsuura et al. (2014), who investigated whether English spoken with an accent less familiar to learners is less comprehensible and found out that that familiarity with the accent facilitates listening comprehension. Both the Nigeria and Ghana accents are African non-native English accents and almost unfamiliar to Chinese English learner. However, the Nigerian accent is peculiar even amongst other African non-native accents. We can assume also that gender difference explained above influenced the participants comprehensibility as the Nigerian accent audio was recorded by a male speaker.

Table 4: Accent preference for Bangladeshi

\begin{tabular}{lll|l|l|l} 
& & & & & \multicolumn{2}{l}{ Cumulative } \\
& & Frequency & Percent & Valid Percent & Percent \\
\hline Valid & 1 & 6.3 & 6.3 & 6.3 \\
\cline { 2 - 7 } & Understandable & 1 & 6.3 & 6.3 & 12.5 \\
\cline { 2 - 7 } & Not understandable & 14 & 87.5 & 87.5 & 100.0 \\
\cline { 2 - 7 } & Total & 16 & 100.0 & 100.0 & \\
\hline
\end{tabular}

Source: Authors

When the participants listen to the Bangladesh English accent first, 15 out of 16 participants could not understand or comprehend at all. The researchers played this audio the third and fourth time. In spite of these efforts, only 1 participant representing $6.3 \%$ answered all questions correctly. The remaining 15 participants failed to answer. They explained the reasons for this as that this audio was not very clear which in turn made it quite difficult to comprehend.

Table 5: Accent preference Italian

\begin{tabular}{lll|l|l|l} 
& & & & & \multicolumn{2}{l}{$\begin{array}{l}\text { Cumulative } \\
\text { Percent }\end{array}$} \\
\hline \multirow{3}{*}{ Valid } & Frequency & Percent & Valid Percent & Percen \\
\cline { 2 - 7 } & & 0 & 0 & 0 & 0 \\
\cline { 2 - 7 } & Understandable & 0 & 0 & 0 & 0 \\
\cline { 2 - 7 } & Not understandable & 16 & 100 & 100 & 100.0 \\
\cline { 2 - 7 } & Total & 16 & 100.0 & 100.0 & \\
\hline
\end{tabular}

Source: Authors 
Last but not least was the Italian English accent. It was undoubtedly the most difficult audio material for the participants to understand. 16 out of the 16 participants barely understood the accent as none answered correctly. Among all the different non-native accents, participants seem to struggle with understanding the Italian accent; this is so because the Italian English accent is heavily accented and quite unfamiliar to the listeners as in tandem with the findings of Matsuura et al. (2014). The second questionnaire consisted of two sections; the first 6 questions were designed to answer research question 2, that is to find out the differences in difficulties participants face while listening to either native being (Chinese) or non-natives and the next 5 questions on their preference ability and their understanding of accents such as Chinese, Ghanaian, Pakistani, Nigerian, Pakistani and Italian. The questionnaire followed 4point Liker scale; 1-Not at all understandable, 2-A little understandable, 3-Understandable and 4-Very understandable. The data for the first section is described below:

Table 6: How do you scale the following English accent?

\begin{tabular}{|c|c|c|c|c|c|}
\hline & $\mathrm{N}$ & Minimum & Maximum & Mean & Std. Deviation \\
\hline Ghanaian & 16 & 2.00 & 3.00 & 2.5333 & .51640 \\
\hline Bangladeshi & 16 & 1.00 & 2.00 & 2.2000 & .56061 \\
\hline Pakistani & 16 & 2.00 & 3.00 & 2.2667 & .45774 \\
\hline Nigerian & 16 & 1.00 & 3.00 & 2.0667 & .45774 \\
\hline Italian & 16 & 1.00 & 1.00 & 1.6667 & 1.17514 \\
\hline Chinese & 16 & 1.00 & 4.00 & 3.2000 & 1.08233 \\
\hline $\begin{array}{l}\text { Valid } \mathrm{N} \quad \text { (list- } \\
\text { wise) }\end{array}$ & 16 & & & & \\
\hline
\end{tabular}

As Anderson-Hsieh and Kohler (1988) concluded, there are various types and strengths of accents, based on Derwing and Munro's (2009) definition, some of which affect the listening comprehension of some listeners and others which do not. As Ockey\& French (2016) mentioned, these studies point to the need for research that provides a clearly defined and defensible measure of accent accompanied by an indication of the strength of accent that impacts listening comprehension. The next question was on how often the learners hear those accents with the scaling, 1-rarely,2-sometimes, 3-often and 4-very often. As the table present-

Table 7: How often do you hear the following English accent?

\begin{tabular}{ll|l|l|l|l} 
& $\mathrm{N}$ & Minimum & Maximum & Mean & Std. Deviation \\
\hline Ghanaian & 15 & 1.00 & 2.00 & 1.7333 & .79881 \\
\hline Bangladeshi & 14 & 1.00 & 2.00 & 1.7857 & .89258 \\
\hline Pakistani & 14 & 1.00 & 2.00 & 1.8571 & .86444 \\
\hline Nigerian & 15 & 1.00 & 2.00 & 1.8000 & .94112 \\
\hline Italian & 15 & 1.00 & 1.00 & 1.8667 & 1.06010 \\
\hline Chinese & 15 & 1.00 & 4.00 & 3.3333 & 1.11270 \\
\hline $\begin{array}{l}\text { Valid N (list- } \\
\text { wise) }\end{array}$ & 14 & & & & \\
\hline $\begin{array}{l}\text { Source: Authors } \\
\text { Suld }\end{array}$ & & & & &
\end{tabular}


The third question was on how often they hear those accents directly and the answer followed the scaling of, 4-Rarely, 3-Sometimes, 2-Often and 1-Very often. Anderson-Hsieh and Kohler (1988) have provided evidence that 'accent' can affect listening comprehension, but that it is not necessarily the case that it does. In their study, the Chinese speakers were assumed to have different accent strengths based on their country of origin and their English language proficiency derived from judgments of their oral proficiency-including pronunciation.

Table 8: How often do you hear the following English accents in the face to face communication?

\begin{tabular}{ll|l|l|l|l} 
& $\mathrm{N}$ & Minimum & Maximum & Mean & Std. Deviation \\
\hline Ghanaian & 15 & 3.00 & 2.00 & 2.5333 & 1.35576 \\
\hline Bangladeshi & 15 & 3.00 & 2.00 & 2.6667 & 1.29099 \\
\hline Pakistani & 15 & 3.00 & 2.00 & 2.6000 & 1.29835 \\
\hline Nigerian & 15 & 4.00 & 2.00 & 2.3333 & 1.29099 \\
\hline Italian & 14 & 4.00 & 1.00 & 2.4286 & 1.45255 \\
\hline Chinese & 15 & 3.00 & 1.00 & 2.3333 & 1.23443 \\
\hline Valid N (listwise) & 14 & & & & \\
\hline Source: Authors & & & & &
\end{tabular}

Here, the table 8 presents that participants preferred Chinese non-native English accent. This is due to their familiarity with their native non-native English accent. Major et al., (2002)in this study found a familiarity effect for Spanish speakers, whose comprehension was higher when listening to an English speaker with a Spanish accent compared to an English speaker with a Chinese accent. This listening familiarity indicates face-to-face conversations.

The fourth question has been described in table 9 below. It was on how difficult they find the following English accent to understand, following the scale, 4-not difficult, 3- not that difficult, 2-difficult and 1-very difficult and the result was:

Table 9: How difficult you find the following English accent to nderstand?

\begin{tabular}{ll|l|l|l|l} 
& $\mathrm{N}$ & Minimum & Maximum & Mean & Std. Deviation \\
\hline Ghanaian & 15 & 2.00 & 3.00 & 2.8000 & .41404 \\
\hline Bangladeshi & 14 & 1.00 & 2.00 & 2.4286 & .75593 \\
\hline Pakistani & 15 & 1.00 & 4.00 & 2.4000 & .82808 \\
\hline Nigerian & 15 & 1.00 & 3.00 & 2.6667 & .81650 \\
\hline Italian & 11 & 1.00 & 1.00 & 2.1818 & 1.32802 \\
\hline Chinese & 15 & 1.00 & 4.00 & 3.3333 & .89974 \\
\hline Valid N (listwise) & 11 & & & & \\
\hline
\end{tabular}

Source: Authors

The difficulty level mainly depends on the familiarity of accents mostly. Harding's (2011) study took this body of research a step further by investigating possible factors that impact comprehension of unfamiliar accents. After corroborating previous research with a finding for greater comprehension of familiar than unfamiliar accents, Harding suggests that this may 
be due to misperception and the lack of ability to distinguish phonetic information or challenges with processing speech. The next question presented in table 10 was central to this current paper. It asked participants to state the English accent noticeably different from what they were used to and they answered following the scale, 4-not different at all, 3- not that different,2-different and 1-very different:

Table 10: According to your opinion which English accent was noticeably ifferent from what you are used to?

\begin{tabular}{ll|l|l|l|l} 
& $\mathrm{N}$ & Minimum & Maximum & Mean & Std. Deviation \\
\hline Ghanaian & 15 & 2.00 & 3.00 & 2.4667 & .51640 \\
\hline Bangladeshi & 15 & 1.00 & 3.00 & 2.3333 & .61721 \\
\hline Pakistani & 15 & 1.00 & 4.00 & 2.6000 & .82808 \\
\hline Nigerian & 15 & 1.00 & 3.00 & 2.4667 & .74322 \\
\hline Italian & 15 & 1.00 & 1.00 & 1.7333 & 1.27988 \\
\hline Chinese & 15 & 3.00 & 4.00 & 3.3333 & .81650 \\
\hline Valid N (listwise) & 15 & & & & \\
\hline
\end{tabular}

Source: Authors

A substantial body of research suggests that familiarity with an accent positively relates to comprehensibility (Gass and Varonis 1984; Derwing and Munro 1997; Adank, et al. 2009; Adank and Janse 2010). Table 10 presents that participants find that the non-native accents are different from the way Chinese learners are habituated to listen and speak English. But they understand the non-native accents mostly accept but not the Italian English accent.

The next question was on Which English accent requires their most concentration to understand and they answered based on the scaling, 4- not require concentration, 3- not require that much concentration, 2- require concentration and 1- require deep concentration:

Table 11: Which English accent requires your most concentration to understand than the usual?

\begin{tabular}{ll|l|l|l|l} 
& $\mathrm{N}$ & Minimum & Maximum & Mean & Std. Deviation \\
\hline Ghanaian & 15 & 1.00 & 3.00 & 2.4000 & .63246 \\
\hline Bangladeshi & 15 & 1.00 & 2.00 & 2.0667 & .59362 \\
\hline Pakistani & 14 & 1.00 & 3.00 & 2.0714 & .61573 \\
\hline Nigerian & 14 & 1.00 & 3.00 & 2.0714 & .73005 \\
\hline Italian & 15 & 1.00 & 1.00 & 1.2000 & .41404 \\
\hline Valid N (listwise) & 14 & & & & \\
\hline
\end{tabular}

Source: Authors

\section{The differences in the difficulties participants face while listening to different accents}

The scale shows the requirement of concentration of the learners' needs due to different factors while understanding a listening test. Bradlow and Brent (2008) suggested that such an effect could result from phonetic characteristics of speech which are known to be rather consistent across speakers who have the same accent. All these tables (6-11) indicate that there are some differences in difficulties learners face while listening to different accents either non-native or native. Native English also varies based on dialects which makes it 
difficult to understand sometimes. The next four questions that the participants answered have been summarized in figure 1 below:

Figure 1: Graphic presentation of Results

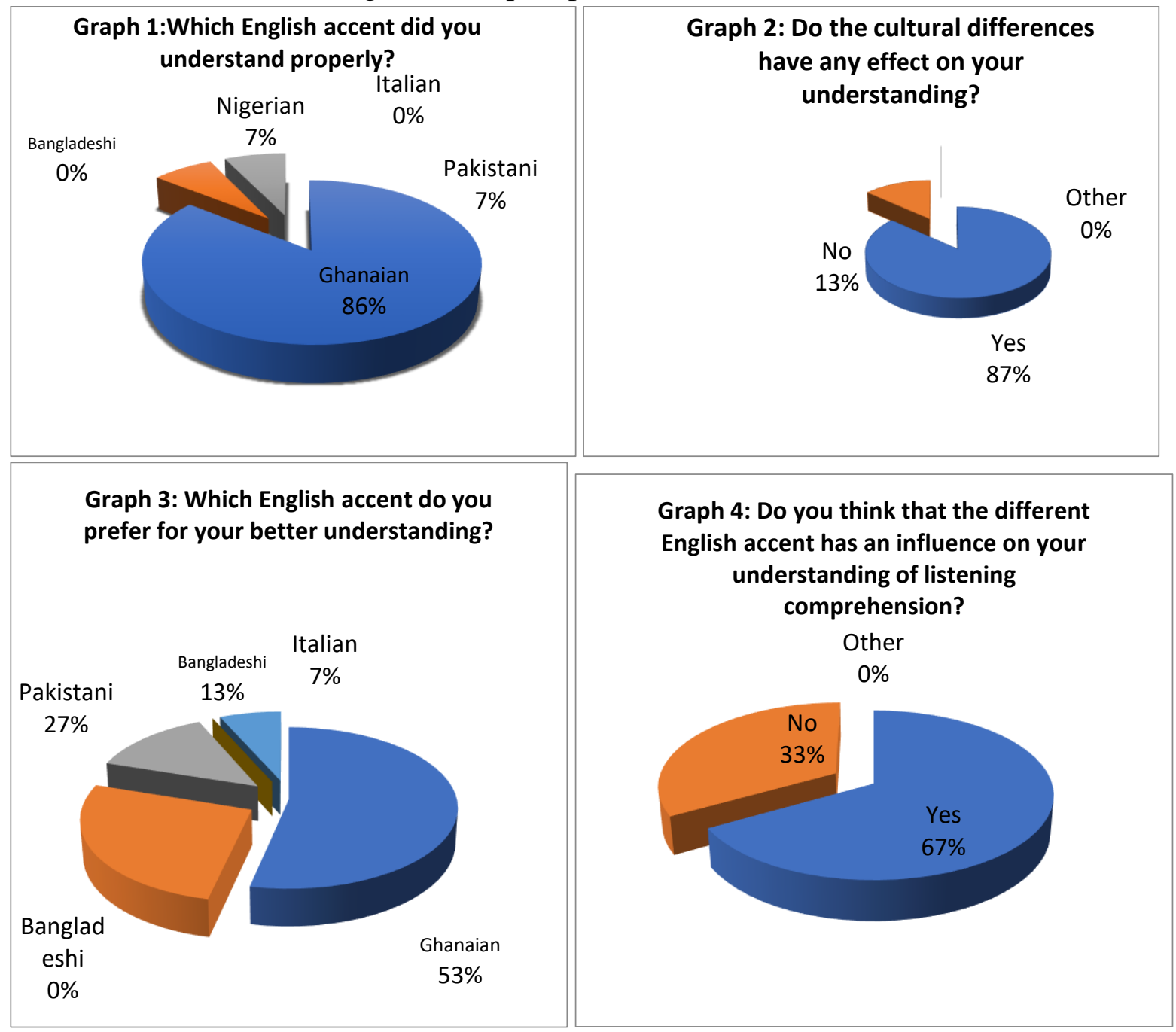

Source: Authors

As shown in figure 1, when the participants were asked about their opinion concerning which non-native accent they understood properly, 86\% indicated they understood the Ghanaian English accent properly. This was followed by Pakistan and Nigerian English accents represented by 7\% each. With regards to Bangladeshi and Italian English accents, most of the respondents indicated they barely understood it as captured in graph 1 .

In grape 3 the English accent they preferred for better understanding seemed to be Ghanaian accent which is $53 \%$ followed by Pakistani accent which is $27 \%$, by Bangladeshi English accent $13 \%$ and Italian English accent being the least preferable, 7\%. This means they provided a positive reaction towards at least the first three accents, as shown in graph 1 and graph 3. Moreover, when participants were asked if cultural differences have any effect on their understanding, about $87 \%$ answered in the affirmative, represented by "yes" as shown in 
graph 2. This however emphasizes the need for the development of cultural and or linguistic diversities within the English accent.

In graph 4, participants were asked if they thought different accents have an influence on their listening comprehension, and about $67 \%$ of participants agreed that different non-native English accents have a great influence on their listening comprehension.

A descriptive analysis of a correlation of these accents is shown below:

Table 12: Non-Native English accents

\begin{tabular}{|c|c|c|c|c|c|c|c|}
\hline & & Ghanaian & $\begin{array}{l}\text { Bangladesh } \\
\mathrm{i}\end{array}$ & Pakistani & Nigerian & Italian & $\begin{array}{l}\text { Chines } \\
\mathrm{e}\end{array}$ \\
\hline \multirow[t]{3}{*}{ Ghanaian } & $\begin{array}{l}\text { Pearson } \\
\text { Correlation }\end{array}$ & 1 & $.685^{* *}$ & $.719^{* *}$ & $.772^{* *}$ & .491 & $.968^{* *}$ \\
\hline & Sig. (2-tailed) & & .005 & .004 & .001 & .063 & .000 \\
\hline & $\mathrm{N}$ & 15 & 15 & 14 & 14 & 15 & 15 \\
\hline \multirow[t]{3}{*}{$\begin{array}{l}\text { Banglade } \\
\text { shi }\end{array}$} & $\begin{array}{l}\text { Pearson } \\
\text { Correlation }\end{array}$ & $.685^{* *}$ & 1 & $.901^{* *}$ & $.760^{* *}$ & $.814^{* *}$ & $.688^{* *}$ \\
\hline & Sig. (2-tailed) & .005 & & .000 & .002 & .000 & .005 \\
\hline & $\mathrm{N}$ & 15 & 15 & 14 & 14 & 15 & 15 \\
\hline \multirow[t]{3}{*}{ Pakistani } & $\begin{array}{l}\text { Pearson } \\
\text { Correlation }\end{array}$ & $.719^{* * *}$ & $.901^{* *}$ & 1 & $.843^{* *}$ & $.639^{*}$ & $.714^{* *}$ \\
\hline & Sig. (2-tailed) & .004 & .000 & & .000 & .014 & .004 \\
\hline & $\mathrm{N}$ & 14 & 14 & 14 & 14 & 14 & 14 \\
\hline \multirow[t]{3}{*}{ Nigerian } & $\begin{array}{l}\text { Pearson } \\
\text { Correlation }\end{array}$ & $.772^{* *}$ & $.760^{* *}$ & $.843^{* *}$ & 1 & $.539^{*}$ & $.729^{* * *}$ \\
\hline & Sig. (2-tailed) & .001 & .002 & .000 & & .047 & .003 \\
\hline & $\mathrm{N}$ & 14 & 14 & 14 & 14 & 14 & 14 \\
\hline \multirow[t]{3}{*}{ Italian } & $\begin{array}{l}\text { Pearson } \\
\text { Correlation }\end{array}$ & .491 & $.814^{* * *}$ & $.639^{*}$ & $.539^{*}$ & 1 & .423 \\
\hline & Sig. (2-tailed) & .063 & .000 & .014 & .047 & & .117 \\
\hline & $\mathrm{N}$ & 15 & 15 & 14 & 14 & 15 & 15 \\
\hline \multirow[t]{3}{*}{ Chinese } & $\begin{array}{l}\text { Pearson } \\
\text { Correlation }\end{array}$ & $.968^{* *}$ & $.688^{* *}$ & $.714^{* *}$ & $.729^{* *}$ & .423 & 1 \\
\hline & Sig. (2-tailed) & .000 & .005 & .004 & .003 & .117 & \\
\hline & $\mathrm{N}$ & 15 & 15 & 14 & 14 & 15 & 15 \\
\hline
\end{tabular}

**. Correlation is significant at the 0.01 level (2-tailed).

*. Correlation is significant at the 0.05 level (2-tailed).

Source: Authors

Table 12 above shows the positive and significant correlation between familiarity of accent, whether native or non-native English accents, and comprehension at 0.01 level (2tailed). This study presents that the non-native English accent is an important topic for further research. This is so because, for example, learner's familiarity with non-native accents, like Chinese English accents, is better understood by Chinese English learners. Although assessing listening comprehension with speakers who have homogeneous accents may under-represent the listening construct, including speakers with multiple accents, it may result in unfairly disadvantaging some test takers (Ockey, 2014). 
Based on the data presented, the study reveals that the reaction of learners of the English language in China to different non-native English accents varies from listener to listener and from speaker to speaker. Nonetheless, when it comes to comprehensibility and understanding, a non-native accent plays a much important role than a native English accent. As shown in the analyses of questionnaire 2(see table 12), all Chinese learners indicated that they preferred the Chinese English accent most among all the non-native English accents mentioned. Hence, it can be concluded that the findings of this study are in line with those of Major et al. (2002), Adank et al. (2009), and Harding (2011), who found a similar accent familiarity advantage. Moreover, the study revealed that non-native English accents were undoubtedly an unavoidable field to work on further, although the effects of listening comprehension did vary and the size of the study quite small. However, given the mildness of the accents used in the study, it is reasonable to conclude that these effects should not be discounted. The study also revealed that the learners understand more or less all non-native English accents. As the participant could scale Ghanaian and Pakistani English accent as their comfort zone to understand, less difficult and less concentration to indulge. It is quite interesting to state that the participants judged the sampled accents as slightly and noticeably different than what the learners used to. Ockey \& French (2016) mentioned the requirement of the learners, to concentrate on listening more than usual and much less than was noticeably different than what they are used to and did require them to concentrate on listening more than normal without decreasing understanding did affect comprehension. Judging the difficulty of accent was found to affect listening comprehension, the second research question related to the extent to which familiarity, the strength of accent, and listening comprehension are related, had increased importance. Finally, it is argued that the relationship lies in Chinese English accents as a familiar accent to rule over other non-native English accents.

\section{Conclusion and Suggestion}

This study investigated the effects of different non-native accents on the listening comprehension of English learners of Chinese. The findings of the study showed a listening comprehension advantage for test-takers who are familiar with accents. The study also revealed that the reaction of learners of the English language in China to different non-native English accents varies from listener to listener and from speaker to speaker. Given these findings, it would be unfair to the participant and professionally irresponsible to use unmeasured accents for listening comprehension assessment inputs. However, it is a threat to the validity of an assessment to use few varieties of non-native English accents to assess English listening comprehension when it is apparent that more variety of speech is commonly encountered in the target language use domain. Given this dilemma, the researchers propose that language researchers and educators make the construct of listening comprehension more multi-accent by including accents that cannot unfairly impact scores.

\section{Limitation and Implications of the Study}

It is important to note that the findings of this study are not over-generalized. All other factors, such as pace, pausing, vocabulary, and speech segment context which could 
conceivably affect a rater's judgment of a speech sample, should be controlled when accent strength is judged and this here can be considered a limitation of the study. This should be considered among speakers of particular varieties of English, grammar and vocabulary very systematically, as accents differ systematically. Regardless of the limits, the study is important for any foreign or second language learning. This is explained for the reason that, English teachers of the world are more or less non-naïve English speakers. For a better understanding of the teaching and learning process, learners or listeners need to assess the influence of non-native accents on their listening comprehension to find better ways in improving their listening skills. For further studies, research should also be towed towards developing the linguistic diversities within the English accent. A study on the extent to which a speaker's utterance is understood by a listener is worthy of investigation when it comes to understanding and observing the overall situation of non-native English teachers of the world. Researchers should also be interested in the relationship between native and or non-native accents and listening comprehension, whether or not familiarity is a factor of incomprehensibility. There is a relation between accent and identity. Researchers should investigate whether or not cultural identities (accents) influence the listener's comprehensibility.

\section{Conflict of Interest}

The authors of the article declare no conflict of interest.

\section{Funding}

This research study was not funded by any institution. The authors conducted the study at their own expenses.

\section{Availability of Data and Material}

The data that support the findings of this study are available from the corresponding author, (Kaniz Fatema), upon reasonable request.

\section{References}

Abeywickrama, P. (2013). Why not non-native varieties of English as listening comprehension test input? RELC Journal, 44/1: 59-74.

Adank, P., Evans, B., Stuart-Smith, J., and Scott, S. (2009). Comprehension of familiar and unfamiliar native accents under adverse listening conditions. Journal of Experimental Psychology, 35/2: 520-529.

Adank, P. and Janse, E. (2010). Comprehension of a novel accent by young and older listeners.Psychology and Aging, 25/3: 736-740.

Anderson-Hsieh, J. and Kohler, K. (1988). The effect of foreign accent and speaking rate on native speaker comprehension. Language Learning, 38/4: 561-613. 
Bilbow, G. T. (1989). Towards an understanding of overseas students' difficulties in lectures: A phenomenon-graphic approach. Journal of Further and Higher Education, 13: 8589.

Bradlow, A. R. and Bent, T. (2008). Perceptual adaptation to non-native speech.Cognition, 106/2: 707-729.

Chen, W. C., \& Lin, W.Y. (2014). Study on the relationship of English listening comprehension to linguistic, cognitive and affective variables among Taiwanese elementary schools students. Accents Asia,(7), 1, pp. 1-27.

Derwing, T. M. and Munro, M. J. (1997). Accent, intelligibility, and comprehensibility: Evidence from four L1s.Studies in Second Language Acquisition, 20: 1-16.

Derwing, T. M. and Munro, M. J. (2009). Putting accent in its place: Rethinking obstacles to communication.Language Teaching, 42/4: 476-490.

Eisentein, M. R. and Berkowitz, D. (1981). The effect of phonological variation on adult learner comprehension.Studies in Second Language Acquisition, 4: 75-80.

Ekong, P. (1982). On the use of an indigenous model for teaching English in Nigeria.World Language English, 1: 87-92.

Elder, C. and Davies, A. (2006). Assessing English as a lingua franca.Annual Review of Applied Linguistics, 26: 282-301.

Gass, S. and Varonis, E. M. (1984). The effect of familiarity on the comprehensibility of nonnative speech.Language Learning, 34/1: 65-89.

Gilakjani, A.P. and Ahmedi, M.R. (2011). A Study of Factors Affecting EFL Learners' English Listening Comprehension and the Strategies for Improvement. Journal of Language Teaching and Research, 2/ 5: 977-988.

Harding (2012). Accent, listening assessment and the potential for a shared-L1 advantage: A DIF perspective. Language Testing, 29(2), 163-180.

Hiroko, M. (2017). Listening to Unfamiliar English Accents: Japanese EFL learners' Perceptions and Comprehension. MATSUURA: Listening to Unfamiliar English Accents. Journal of Commerce, Economics and Economic History. 86/ 1:1-11.

Lasagabaster, D., \& Manuel Sierra, J. (2005). What do students think about the pros and cons of having a native speaker teacher? In E. Llurda (Ed.), Nonnative language teachers: Perceptions, challenges, and contributions to the profession (pp. 217- 242). New York, NY: Springer.

Major, R., Fitzmaurice, S. M., Bunta, F., \&Balasubramanian, C. (2002). The effects of nonnative accents on listening comprehension: Implications for ESL assessment. TESOL Quarterly, 36, 173-190.

Major, R., S. Fitzmaurice, Bunta, F., and Balasubramanian C. (2002). The effects of nonnative accents on listening comprehension: Implications for ESL assessment. TESOL Quarterly, 36/2: 173-190.

Mahboob, A., \& Golden, R. (2013). Looking for native speakers of English: Discrimination in English language teaching job advertisements. Voices in Asia Journal, 1(1), 72-81.

Munro, M. J., and Derwing, T. M. (1995a). Foreign accent, comprehensibility and intelligibility in the speech of second language learners.Language Learning, 45: 7397. 
Munro, M. J. and Derwing, T. M. (1995b). Processing time, accent, and comprehensibility in the perception of native and foreign-accented speech.Language and Speech, 38/3: 289-306.

Ockey G. and French R. (2014).From One to Multiple Accents on a Test of L2 Listening Comprehension. Applied Linguistics, V.35), 7, Pg. 693-715.

Ortmeyer, C. and Boyle, J. (1985). The effect of accent differences on comprehension.RELC Journal, 16/2: 48-53.

Pennington, M. C. (1996). Phonology in English Language Teaching. Longman. Schmid, P. and G. Yeni-Komshian. 1999. The effects of speaker accent and target predictability on the perception of mispronunciation. Journal of Speech, Language, and Hearing Research, 42: 56-64.

Smith, L. and J. Bisazza (1982). The comprehensibility of three varieties of English for college students in seven countries.Language Learning, 32/2: 259-269.

Tauroza, S. and Luk, J. (1997). Accent and second language listening comprehension.RELC Journal, 28: 54-71.

Taylor, L. (2006). The changing landscape of English: Implications for English language assessment. ELT Journal, 60/1: 51-60.

Taylor, L. and A. Garenpayeh. (2011). Assessing English for academic purposes: Defining and operationalizing the test construct.Journal of English for Academic Purposes, 10: 89-101.

Selvi (2014). Myths and Misconceptions about Nonnative English Speakers in the TESOL (NNEST) Movement. TESOL Journal, 5(3), 573-611.

Elder, C. and Harding L. (2008). Language testing and English and an international language: Constraints and contributions in Sharifian, F. and M. Clyne (eds.): Australian Review of Applied Linguistics (special forum issue), 31/3: 34.1-34.11.

Clarke, C. M. and Garrett, M. F. (2004). Rapid adaptation to foreign-accented English.Journal of the Acoustical Society of America, 116: 3647-3658.Department of Institutional Research. Faculty by ethnic group. http://www.irs.ttu.edu/NEWFACTBOOK/ Faculty/2007/F07ETHNIC.html

"From One to Multiple Accents on a Test of L2 Listening Comprehension," (2014) 1-24 is available online at http://dx.doi.org/10.1093/applin/amu060.

Bachman, L. F., \& Palmer, A. S. (1996). Language Testing in practice. Oxford University Press.

Buck, G. (2001). Assessing Listening. Cambridge University Press.

Harding, L. (2011). Accent and Listening Assessment: A Validation of the Use of Speakers with L2 Accents on Academic English Listening Test. Peter Lang.

Keppel, G., and T. Wickens. 2004. Design and Analysis: A Researcher's Handbook (4 ${ }^{\text {th }}$ Ed.). Pearson-Prentice Hall.

Seidlhofer, B. 2003. A Concept of International English and Related Issues: From 'Real English' to 'Realistic English? in Language Policy Division, Council of Europe, Strasbourg.

Mahboob, A., Uhrig, K., Newman, K. L., \& Hartford, B. S. (2004). Children of lesser English: Status of nonnative English speakers as college-level English as a second 
language teachers in the United States. In L. Kamhi-Stein (Ed.), Learning and teaching from experience: Perspectives on nonnative English-speaking professionals (pp. 100-120). Ann Arbor: University of Michigan Press.

Mahboob, A. (2010). The NNEST lens: Nonnative English Speakers in TESOL. Newcastle upon Tyne. England: Cambridge Scholars Publishing.

Field, J. (2004). Pronunciation acquisition and individual learner. Presentation at the IATEFL Joint Pronunciation and Learner Independence Special Interest Groups Event, University of Reading, 26 June 2004.

Guo, N. and Wills, R. (2005). An Investigation of Factors Influencing English Listening Comprehension and Possible Measures for Improvement. Paper Presentation at the AARE Annual Conference Parramatta 2005. 